\title{
Una plegaria por la risa
}

El humor es la manera de ver las cosas con claridad.

Antonio Mingote (humorista español)

\author{
Carlos Bejarano
}

\begin{abstract}
$\bigwedge^{a ́ s}$ que un análisis, un estudio, una reflexión, un tratado o un simple comentario, quisiera que las siguientes líneas tomen la forma de una oración. Una sentida plegaria cartuja o trapense, no sé, que me permita agradecer a todos aquellos que en Lima, Nueva York o Buenos Aires se dedicaron al noble oficio de ridiculizar a los políticos. Ellos, los humoristas, más que el sociólogo, el politólogo o el economista, son los que realmente ponen en su sitio al legislador violador que se justifica diciendo que "son cosas que pasan"; a su colega que niega tener una hija y luego le sale otra y otra, $y$ al final tiene que reconocer a tres; al congresista que se burla de la autoridad y tira a la basura resoluciones; al que dice tener una biblioteca de un millón de dólares, pero señala que "más antes no estaba tan bien"; a los sobrinos del presidente, al "violín" y al "borracho"; a la Primera Dama; en fin, a todos aquellos que han hecho suya la frase: "Esta es la república peruana, donde cada quien hace lo que le da la gana”. A ellos mi homenaje.
\end{abstract}

Año 2000: periodistas, políticos, empresarios, militares y hasta purpurados son vinculados a la red mafiosa más grande que se haya conocido en 
nuestro país. Todos los canales de televisión privados - 2, 4, 5, 9 y 13- tuvieron y tienen relaciones con Vladimiro Montesinos, y nadie cree en lo que dicen. La pauta informativa de los noticieros se hace a gusto del cliente. Una semana el informativo de Panamericana Televisión dice que Ernesto Schultz es un perseguido político; la otra, el mismo canal, ahora con diferente administración, lo llama delincuente. Todo está cuestionado. En las esquinas los titulares de los periódicos y revistas no hacen sino refrendar la crisis de credibilidad que ataca al país. Incluso el empresario más poderoso del Perú es acusado de haberse beneficiado de su amistad con Vladimiro Montesinos y el Poder Judicial, una vez más, es cuestionado y su nivel de confianza, como siempre, es bajo. ¿A quién le creemos entonces?

De ese miasma social emergen Guillermo Rossini, Fernando Armas y Hernán Vidaurre. Ellos son una respuesta espontánea a esa crisis de representatividad que invade el país. Tal vez sin darse cuenta fueron los únicos que, imitando y burlándose, pusieron en su lugar a los malhechores y a quienes no hacían bien su trabajo. Mientras los jueces, con su pachocha de siempre, buscan la punta del enrevesado ovillo de la corrupción fujimontesinista, y el Congreso sigue formando megacomisiones para investigar a la mafia, el trío desenreda el ovillo, lo pone en un carrete y sienta a la mafia en el banquillo para someterla a un juicio de humor.

Gracias a ellos escuchamos decir a Laura Bozzo que Montesinos era una basura, a Fujimori que regresará el 2006 y al "Doc" recordarle a Mantilla el dinero que le dio. Pepas que cualquier periodista envidiaría y que solo podemos escuchar en la voz, gesto e imaginación de Los Chistosos. Cosas que sabemos son ciertas, pero ni la justicia ni nadie es capaz de probarlas. Solo el humor nos salva.

La importancia de este trío fue tal, que según una encuesta realizada por el Grupo Apoyo en septiembre del 2002, el 61 por ciento de limeños consideraba a los humoristas como los comunicadores más independientes, porcentaje curiosamente mayor del que le otorgaban a RPP, medio en el que trabajan. La fuerza de estos personajes fue incluso tabulada por Vladimiro Montesinos, como queda claro en el siguiente diálogo:

MonTESINOS. - RPP tiene mucha sintonía, bastante sintonía.

Bedoya de Vivanco. — Sí, es la radio que más sintonía tiene.

Gonzales Reátegui. -Están ahí Los Chistosos.

MONTESINOS. - Claro.

Gonzales Reátegui. —Están los personajes de Los Chistosos.

Tal vez Montesinos no se interesó por intentar "comprar" la opinión de 
Los Chistosos, porque consideró que podía servir como muestra de la tolerancia del régimen. Quizá, salvando la distancia, algo parecido a lo ocurrido a la dictadura argentina con la revista Humor.

No quiero continuar sin hacerme una pregunta que a estas alturas suena lógica: ¿Por qué en nuestro país el humor político ha transitado básicamente por canales y radios y no tuvo un éxito similar en la prensa? Habría que decir que, salvo Monos y Monadas, genial propuesta de Nicolás Yerovi, y en algún momento el suplemento No de la revista Sí, en los últimos 30 años no hubo, en todo caso no recuerdo, alguna presencia importante en este rubro. Con respecto a la revista No habría que hacer la salvedad de que aunque fue una propuesta de primer nivel, que juntó a un grupo de notables caricaturistas, en realidad su éxito fue relativo, pues era un anexo de la revista Sí.

Dudo de que No hubiera tenido éxito si se vendía sola. En el caso de Monos y Monadas la propuesta fue muy osada y tal vez exagerada para la realidad nacional. Su nivel cuando no era bueno era excepcional, pero no sé si eso se reflejaba en las ventas. Aquí es bueno resaltar el trabajo de Nicolás Yerovi, tanto por su nivel organizativo como productivo. No conozco escritor tan prolífico y compulsivo como Nico. No quiero herir susceptibilidades, pero Monos y Monadas era él.
Finalmente, creo que esa ausencia sostenida de revistas de humor se debe principalmente, si nos comparamos con Argentina, entre otras cosas, al nivel de lectoría de ambos países. Por estas tierras la lectura no interesa, no sirve, aburre; así venga con dibujitos.

Algún caricaturista podrá reclamar por el gremio y por supuesto que tendrá algo de razón, pues todo medio que se precie tiene alguien que se dedica al humor político. Sin embargo, el inconveniente es que el trabajo en diarios siempre dependerá de la línea editorial. Creo que Heduardo, Carlín y Alfredo -básicamente ellos tres-realizan trabajos que sin ningún temor pueden calificarse de geniales. Sin embargo, su aporte es complementario. Y que no se enojen. Aunque el efecto de una caricatura puede ser letal, su peso es distinto al de cualquier producción audiovisual. Y la explicación es simple, se debe a una palabra maldita y bendita al mismo tiempo, que de igual manera puede contener el cielo y el infierno, el bien y el mal, el yin y el yang: rating. Mientras en la televisión y la radio la estabilidad de los programas depende del rating, en los medios escritos se supedita a la línea editorial. No quiero entrar en detalles, pero el rating es contundente y no acepta negociaciones.

Un amigo que es caricaturista principal en un tradicional diario me contaba que sus mejores trabajos nunca se publicaban, pues al jefe de la página le 
parecían muy osados, algo que sin embargo mi amigo aceptaba sin chistar, pues le parecían gajes del oficio. Afortunadamente esos geniales trabajos no se perdían pues los terminaba colgando en la red.

Entonces, nuestro humor político es principal y casi exclusivamente de radio y televisión.

Otra pregunta: ¿Siempre se debe hacer humor político, o debe haber ciertas condiciones para que este prenda en el gusto popular? Se me ocurre que esta es una pregunta clave para cualquiera que se dedique a este oficio. Al parecer, no siempre una parodia, imitación, apodo o chiste sobre un político tiene buena recepción. Shakespeare decía que el éxito de un chiste dependía de quien lo oía y no de quien lo decía; es decir que el humorista debe saber medir aquel concepto que el filósofo posmoderno Pocho Rospigliosi definía como "eso que le gusta a la gente". Solo así logrará personajes y chistes exitosos. Debe saber en qué momento se hace humor y sobre quién. Por ejemplo, los argentinos, que parecen tener facilidad para el humor y la irreverencia, tuvieron una época de seca, de silencio en lo que a humor político se refiere, cuando en 1983 Raúl Alfonsín asumió la presidencia. Al parecer, tuvieron el tacto suficiente para saber que después de una dictadura tan dura, no se podía brome- ar. Sobre los militares se podía decir casi de todo, pero no había ganas de bromear sobre el Presidente. Los pocos que se atrevieron lo hicieron con mucho respeto.

Otra regla de oro es que no se puede hacer humor político desde el canal del Estado. Por más que se diga que es la señal de todos, es muy difícil que un proyecto así tenga éxito. El ejemplo más claro es el de Tulio Loza y Carlos Álvarez. Aquí es bueno resaltar el caso del último. Luego de ser acusado de haber recibido dinero de Montesinos durante el tiempo que trabajó en Canal 7, empieza a recobrar terreno y casi vuelve a ser el líder de opinión de antes. Sobre las acusaciones, que seguirán el rumbo que determine la justicia, no quiero pronunciarme, pero sí quiero resaltar su paso por Canal 7. Si algo caracteriza a quienes se dedican a criticar al sistema es la independencia, su alejamiento del poder, o por lo menos hacerle creer a la gente que es así. En el caso de Álvarez y Loza, dos humoristas con talento suficiente para hacer un buen programa, su paso por el canal del Estado fue poco menos que lamentable. Ninguno repitió sus éxitos anteriores por un hecho que me parece simple y contundente: la gente los percibió muy cerca de ese poder del que siempre se burlaron. Es decir que se quedaron sin su insumo principal: el Ejecutivo. Nadie puede creer que un cómico pagado por el Ejecutivo se pueda bur- 
lar de él. Camotillo el Tinterillo, ese genial personaje de Tulio Loza y Polo Campos, no merecía ver a su creador en esos trances. Una pena, pues será muy difícil resucitar al genial discursero, aunque en estos terrenos no hay que ser contundentes.

Para terminar, quiero reflexionar sobre el uso del humor en el periodismo político. Es notoria la gran incapacidad que tienen nuestros comentaristas "serios" para incorporar el humor en su discurso. No recuerdo a ninguno usando el humor como esa arma contundente, la más grande virtud del ser humano, según Edward de Bono. Es como si un comentario de este tipo le quitara seriedad a cualquier discurso. Como si desconocieran el poder contundente de una broma que ridiculiza, humilla y destruye a cualquiera. En Argentina, por ejemplo, nuestro inevitable referente cultural, es común encontrarse con un periodista "serio" que se permita burlarse del poder y de quienes lo administran. Desde CQC, programa de humor político que realizaba investigaciones con una rigurosidad admirable, hasta conductores líderes como Ernesto Lanatta, que despotrican contra el sistema como lo haría cualquier hijo de vecino (con lisuras mayormente) son varios los ejemplos de irreverencia. La pregunta es: ¿por qué nuestros comunicadores le dan un aire de solemnidad a sus comentarios?, ¿será por ellos mismos o porque la gente, el oyente, la audiencia no permiten un comentario de humor? ¿Nuestro humor es distinto, por ejemplo, al rioplatense?

Muchas preguntas, muchas interrogantes y tal vez mucha teoría sobre el humor, cuando de lo que se trata es de reír. Más que una conclusión, epílogo, colofón o resumen, para terminar con una sonrisa, me he permitido escoger las opiniones, comentarios, análisis y elucubraciones del humorista político del momento: George W. Bush.

"La gran mayoría de nuestras importaciones vienen de fuera del país".

"Si no tenemos éxito, corremos el riesgo de fracasar".

"Marte está esencialmente en la misma órbita... Marte está más o menos a la misma distancia del Sol, lo que es muy importante. Nosotros tenemos fotos donde existen canales, pensamos, es agua. Si hay agua, eso significa que hay oxígeno. Si hay oxígeno, significa que podemos respirar".

"El Holocausto fue un período obsceno en la Historia de nuestra nación. Quiero decir, en la Historia de este Siglo. Pero todos vivimos en este siglo. Yo no viví en ese siglo".

"Yo creo que nos dirigimos de modo irreversible hacia la libertad y democracia pero eso puede cambiar".

"Una palabra resume probablemente la responsabilidad de cualquier go- 
bernante. Y esa palabra es estar preparado".

"El futuro será mejor mañana".

"Nosotros vamos a tener el pueblo americano mejor ilustrado del mundo".

"Personas que son realmente muy extrañas pueden asumir posiciones clave y provocar un terrible impacto en la Historia".

"Yo mantengo todas las declaraciones equivocadas que hice".

"Nosotros tenemos un firme compromiso con la OTAN. Nosotros formamos parte de la OTAN. Nosotros tenemos un firme compromiso con Europa. Nosotros formamos parte de Europa".

"Un número bajo de votantes es una indicación de que menos personas están yendo a votar".

"Cuando me preguntaron quién provocó la revuelta y las muertes en Los Ángeles, mi respuesta fue directa y simple: ¿A quién debemos culpar por la revuelta? A Los revoltosos. Los revoltosos son los culpables. ¿A quién debe- mos culpar por las muertes? Los que mataron son los culpables".

"Ilegitimidad es algo que deberíamos hablar en términos de no tenerla".

"Nosotros estamos preparados para cualquier imprevisto que pueda ocurrir o no".

"Para la Nasa, el espacio aún es alta prioridad".

"Francamente, los profesores son los únicos profesionales que enseñan a nuestros niños".

"El pueblo americano no quiere saber de ninguna declaración equivocada que George Bush pueda hacer o no".

"Todos somos capaces de errar pero yo no estoy preocupado en esclarecer los errores que puedo haber $\mathrm{CO}^{-}$ metido o no".

"No es la polución lo que está perjudicando el medio ambiente. Son las impurezas en nuestro aire y agua que hacen eso".

"Es tiempo para la raza humana de entrar en el sistema solar". 